\title{
A review of the health effects of smoking shisha
}

\author{
Authors: Murtaza Kadhum, ${ }^{A}$ Abed Sweidan, ${ }^{B}$ Ali Emad Jaffery, ${ }^{C}$ Adam Al-Saadi ${ }^{D}$ and Brendan Madden ${ }^{E}$
}

There is emerging evidence, although at early stages, of various detrimental health effects after smoking shisha. With regard to the cardiovascular system, there is a significant acute rise in cardiovascular markers, such as heart rate and blood pressure. The long-term effects on the cardiovascular system are yet to be established. Shisha smoking has also been significantly associated with lung cancer. Various other forms of cancer have also been documented, but have not reached statistical significance and require further research. Finally, shisha smoking increases the risk of infection and has been associated with outbreaks in the Middle East. Therefore, with the increasing consumption of shisha in Europe, especially in the UK, more research is required to tackle this potential public health threat.

KEYWORDS: Shisha, hookah, smoking, tobacco, public health, cardiorespiratory

\section{Introduction}

Shisha is a method of smoking tobacco invented in the 16th century by a physician named Hakim Abul-Fath Gilani. The purpose of the device was to pass smoke through water in an attempt to 'purify' the smoke, an unproven concept that has been repeatedly questioned by the medical community. ${ }^{1}$

The underlying mechanism of a shisha device has remained constant throughout history (Fig 1). However, its assembly has become significantly simpler. Shisha consists of a head that contains tobacco separated from an array of coal by foil. ${ }^{1}$ The head is connected to a system of air tight pipes that draw tobacco smoke into a bowl which contains water. Then, as the user inhales through the hose, smoke is drawn in from the bowl to the smoker. ${ }^{1}$ Interestingly, the practice of shisha has changed in multiple ways. For example, the substance smoked has evolved from simple tobacco to the addition of flavouring such as apple, grape and mint. In addition, shisha smoking has become increasingly available, mainly as a result of a growing number of shisha-serving venues and cheaper prices. Since

Authors: Amedical student, St. George's, University of London,

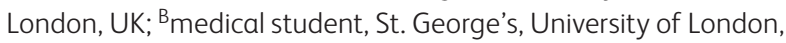
London, UK; Cmedical student, St. George's, University of London, London, UK; D medical student, St. George's, University of London, London, UK; Eprofessor of cardiothoracic medicine, St. George's, University of London, London, UK

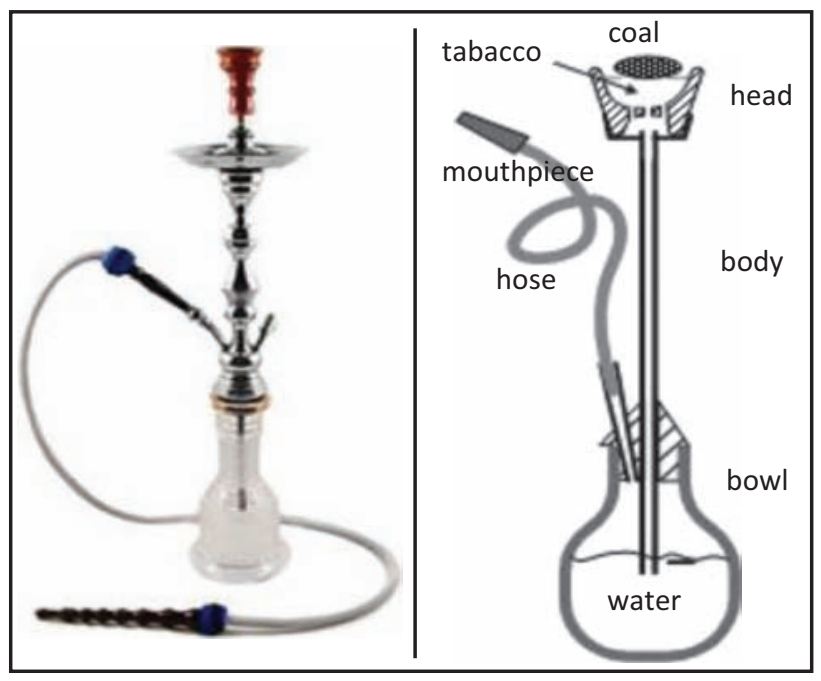

Fig 1. The shisha apparatus (left) and a labelled schematic of the main parts (right). Reproduced with permission. ${ }^{1}$

the smoking ban in the UK, shisha consumption has risen by approximately $210 \% .^{2}$ This rise in consumption has likely been aided by the increase in the number of shisha cafes from 179 to 556 between 2007 and 2012. ${ }^{2}$ This is indicated by the presence of 'shisha streets' across the UK, such as Edgware Road in London, where shisha cafes are co-located in close proximity to Middle Eastern and Asian restaurants.

Despite the belief that shisha allows the smoker to inhale purified smoke, a misconception that remains prevalent in society today, shisha has been shown to be associated with a wide range of detrimental health effects. Research has been carried out comparing shisha to cigarette smoking in an attempt to provide an evidence-based comparison between them. One study conducted in London in 2013 described shisha smoking as acutely stressful to the cardiovascular system in a similar way to cigarettes, supporting the fact that the action of passing the smoke through water is not 'purifying. ${ }^{3}$ These studies are currently very limited in number, relative to studies on cigarette smoking. Interestingly, a recent study described a disparity among GPs' knowledge of shisha and its effects. ${ }^{4}$ Here, $36 \%$ of GPs described smoking shisha as equivalent to 16-20 cigarettes, while $20 \%$ of GPs believed smoking shisha was equivalent to $0-5$ cigarettes. ${ }^{4}$ Therefore, there is a clear need for more research regarding the health effects of shisha smoking, in order to provide an accurate evidence base. 
The general attitude towards smoking shisha is disproportionately lax compared to that of smoking cigarettes. For example, a study of medical students in Malaysia found that a significant proportion of the participants believed that shisha smoke does not contain nicotine or carbon monoxide (CO), and that smoking shisha does not lead to respiratory, dental or cardiovascular morbidity. ${ }^{5}$ This study also found that a higher proportion of the smoking participants lived in urban areas and that $20 \%$ of the students in the medical school smoked shisha. This prevalence of shisha smoking among medical students is similar in various other countries, such as the UK, US and Pakistan. ${ }^{5-7}$ Furthermore, in Saudi Arabia, it was found that $50 \%$ of students thought that smoking shisha was less harmful then smoking cigarettes, $61 \%$ of which thought that harmful substances were purified by water filtration. ${ }^{8}$ These misconceptions are reinforced by the fact that shisha smoking is a sociable activity; and a cultural norm in many countries. Furthermore, due to the use of flavourings, shisha smoking leaves a pleasant smell, unlike cigarettes. This discrepancy in public opinion is prevalent among the young adult and teenage population of the UK, and has played a major role in the exponential rise in shisha popularity. ${ }^{9}$ These lay beliefs have unfortunately maintained themselves despite the campaigns against shisha smoking and action by local councils. A more extensive programme is required to improve awareness regarding the health effects of smoking shisha, especially in the teenage and young adult population.

\section{Constituents of shisha smoke}

Shisha smoking involves burning flavoured tobacco, known as molasses, using coal. When an individual breathes in from the mouthpiece, air is pulled through the apparatus into the tobacco and heated by the coal to produce smoke. As a result, the smoke contains components from both the tobacco and coal. These include polycyclic aromatic hydrocarbons $(\mathrm{PAH})$, volatile aldehydes, $\mathrm{CO}$, nitric oxide $(\mathrm{NO})$, nicotine, furans and nanoparticles. ${ }^{10}$

Both tobacco-containing and tobacco-free molasses contain high levels of PAH, a carcinogenic compound..$^{11}$ These high levels are caused mostly due to the combustion of coal. ${ }^{11}$ Coal is generally found either in lumps or briquettes. ${ }^{11}$ Lump coal is found in various forms, sizes and originates from biomass. The briquette form can be found as either 'easy-light', which contains an ignition agent, or as a coconut-shell based product. ${ }^{11}$ All these forms of coal contain high levels of PAH residues, especially benzo(a)pyrene, a potent carcinogen. ${ }^{11}$ Interestingly, in one study, the coconut-shell based coal contained approximately six times more $\mathrm{PAH}$ products than any other type of coal. ${ }^{11}$ Lump coal was shown to contain the least amount of $\mathrm{PAH}{ }^{11}$. This significant exposure to $\mathrm{PAH}$ may be causal in the development of various malignancies after shisha smoking. ${ }^{11}$

The presence of volatile aldehydes has also been reported in shisha smoke, including formaldehyde, acetaldehyde, acrolein, propionaldehyde and methacrolein. ${ }^{12}$ These chemicals have been correlated with various respiratory disorders, respiratory tract irritation, chronic obstructive pulmonary disease and lung cancer. ${ }^{12}$ Specifically, formaldehyde and acrolein are both potent carcinogens that may promote the development of leukaemia. ${ }^{12}$ The approximate levels of volatile aldehydes in shisha smoke have been found to be significantly higher than in cigarettes, highlighting that shisha may result in a higher incidence of aldehyde-associated diseases. ${ }^{12}$

In addition, $\mathrm{CO}$ levels have been observed to significantly increase after shisha smoking. Typically, carboxyhaemoglobin concentrations are greater than $10 \%$ in shisha smokers, compared with $6.5 \%$ in cigarette smokers and $1.6 \%$ in nonsmokers. ${ }^{13}$ One recent study also noted that acute levels of CO increased significantly, possibly contributing to $\mathrm{CO}$ poisoning. ${ }^{3}$ In these cases, carboxyhemoglobin levels can reach between $20-30 \%$ and patients may present with a loss of consciousness, headaches and shortness of breath. ${ }^{13}$

Nicotine levels increase significantly from 2 to $6 \mathrm{ng} / \mathrm{ml}$ after smoking shisha for five minutes. Increasing nicotine levels have been shown to induce increases in heart rate and may contribute to various cardiovascular diseases. ${ }^{14}$

\section{The health effects of smoking shisha}

Smoking shisha is associated with three main detrimental health effects: cardiovascular damage, infection and cancer formation (Table 1). Much of the morbidity and mortality associated with shisha smoking can be attributed to impairment of the cardiovascular system. It is important to note that in some studies studying the effects of shisha smoking, regular cigarette smokers were not excluded. Therefore, the results observed may have been due to a combined biological effect of both cigarette and shisha smoke.

Shisha smoking has been reported to disrupt the autonomic regulation of the cardiac cycle, by causing an acute reduction in heart rate variability. ${ }^{10}$ This may be associated with an increased susceptibility to arrhythmia, systemic inflammation and risk of coronary heart disease. ${ }^{10}$ A positive association between coronary artery disease and shisha smoking was reported although the study did not demonstrate statistical

Table 1. Summary of the potential health effects of smoking shisha. 3,15,20,21,23-26

\begin{tabular}{|c|c|}
\hline $\begin{array}{l}\text { Reported risks of } \\
\text { smoking shisha }\end{array}$ & Effect \\
\hline \multirow[t]{2}{*}{$\begin{array}{l}\text { Cardiovascular } \\
\text { system damage }\end{array}$} & $\begin{array}{l}\text { Increased risk of arrhythmia, due to } \\
\text { reduction in heart rate variability }\end{array}$ \\
\hline & $\begin{array}{l}\text { Increased risk of coronary heart disease } \\
\text { due to dysregulation of platelet } \\
\text { homeostasis, reduction in HDL levels, } \\
\text { increase in LDL levels, systolic BP, diastolic } \\
\text { BP and heart rate }\end{array}$ \\
\hline Infection & $\begin{array}{l}\text { Increased risk of hepatitis, herpes and } \\
\text { tuberculosis infection by sharing } \\
\text { mouthpieces }\end{array}$ \\
\hline \multirow[t]{3}{*}{ Cancer } & > Quadruples risk of lung cancer \\
\hline & $\begin{array}{l}\text { Positive association with formation of } \\
\text { bladder, prostate, nasopharyngeal and } \\
\text { oesophageal cancer }\end{array}$ \\
\hline & $\begin{array}{l}\text { Positive association with oral dysplasia, } \\
\text { squamous cell carcinoma and } \\
\text { keratocanthoma of the lip }\end{array}$ \\
\hline
\end{tabular}


significance. ${ }^{14}$ Interestingly, serum concentrations of highdensity lipoprotein (HDL)-cholesterol and apolipoprotein (apo) A-1 were found to be significantly lower in shisha smokers than in non-smokers. ${ }^{15}$ Moreover, low-density lipoprotein (LDL)cholesterol, apo B, triglycerides and malondialdehyde were significantly higher in shisha smokers than in non-smokers. ${ }^{15}$ Total antioxidant capacity and vitamin $\mathrm{C}$ were also found to be significantly lower in shisha smokers than in non-smokers. ${ }^{15}$ These findings may implicate shisha smoking as a risk factor for coronary heart disease.

In a previous study we conducted, systolic blood pressure, diastolic blood pressure, heart rate and CO levels were all observed to rise significantly after smoking shisha. ${ }^{3}$ These results were also observed in studies from Jordan and the United Arab Emirates. ${ }^{16}$ The parameters described above were notably higher in shisha smokers, compared with cigarette smokers. ${ }^{3}$ Ultimately, in chronic shisha smokers, systolic blood pressure and heart rate remain significantly elevated. ${ }^{17}$ People who smoked both shisha and cigarettes were reported to have the highest mean systolic blood pressure and heart rate, across all age groups. ${ }^{17}$

$\mathrm{NO}$, a vasodilator, was found at a significantly higher serum concentration in shisha smokers $(34.3 \mu \mathrm{mol} / \mathrm{l})$ compared with non-smokers $(22.5 \mu \mathrm{mol} / \mathrm{l}) .{ }^{18}$ It was reported that shisha smokers showed impaired vasodilation of the brachial artery in response to shear stress, compared with that of cigarette smokers and non-smokers. ${ }^{19}$ This impaired vasodilation could potentially lead to vascular remodelling and dysfunction.

Wolfram et al showed that a single shisha smoking session significantly affected platelet function. ${ }^{20}$ The induced injury was marked by an elevation of both 8-epi-prostaglandin F2 alpha and malondialdehyde, which are both markers for in vivo oxidation injury. ${ }^{20}$ 11-Dehydrothromboxane B2, a parameter of platelet homeostasis, was also found to be elevated after a single smoking session. ${ }^{20}$ Interestingly, the study also reported that consistent daily smoking resulted in a persistent longer lasting oxidation injury. ${ }^{20}$ This homeostatic imbalance in shisha smokers may possibly cause platelet aggregation and could increase the likelihood of atherothrombotic cardiovascular events.

There is a substantial risk of infection with herpes, hepatitis and tuberculosis (TB) after smoking shisha. Often, shisha is smoked in large groups, rather than as individuals. ${ }^{21}$ By sharing mouthpieces, various commensal and pathogenic organisms may be transmitted between the smokers through saliva. ${ }^{21}$ Recently, shisha cafes provide a plastic disposable mouthpiece to every customer, which aims to limit the spread of communicable diseases. The risk of infectious disease also increases due to the moist nature of shisha molasses, creating an environment that promotes growth of many different microorganisms. ${ }^{21}$ Lastly, although well-run shisha cafes regularly wash their shisha pipes, the relatively rigid and complicated structure of the shisha apparatus makes it virtually impossible to efficiently wash the internal aspects. ${ }^{21}$ For example, TB may grow and survive on the internal surface of the shisha pipe and water, significantly increasing risk of transmission. ${ }^{22}$ In the Middle East, outbreaks of infectious disease have been correlated with shisha smoking. Akl et al described two outbreaks in 2010, which revealed a possible association between TB and sharing a shisha pipe. ${ }^{23}$

In a similar way to cigarette smoking, shisha smoking introduces many harmful chemicals and free radicals into the body, many of which have been implicated in cancer development. For example, one study revealed that smoking shisha quadruples the risk of lung cancer, when compared to non-smokers. ${ }^{23}$ Other studies also reported that there was an association of shisha smoking with bladder cancer, prostate cancer, squamous cell carcinoma and keratoacanthoma of the lip, nasopharyngeal cancer, oesophageal cancer and oral dysplasia. ${ }^{23-26}$ However these associations were not statistically significant.

\section{Conclusion}

Shisha has surged in popularity in the last decade, especially in the UK. In London specifically, since the smoking ban in 2007, there has been a $210 \%$ increase in the number of cafes serving shisha. At present, there is substantial confusion regarding the health effects of smoking shisha by healthcare professionals and consumers. Interestingly, recent studies have concluded that shisha smoking leads to significant exposure to PAHs, volatile aldehydes, $\mathrm{CO}, \mathrm{NO}$, nicotine, furans and nanoparticles. These agents have a wide range of effects ranging from cancer formation to respiratory disorders. Furthermore, smoking shisha also carries a cardiovascular risk, leading to a significant acute increase in blood pressure, heart rate and CO levels. Various studies have also described a shisha-induced reduction in heart rate variability, which may contribute to an increased risk of coronary artery disease development. This risk may be further exacerbated by a shisha-induced reduction in HDLcholesterol levels. Smoking shisha has also been associated with increased rates of infection, namely tuberculosis, herpes and hepatitis. Fundamentally, this is caused by sharing mouthpieces while smoking, allowing for commensal and pathogenic organisms to be transmitted between the different users. Finally, a statistically significant association between smoking shisha and the development of lung cancer has been reported, mainly driven by exposure to carcinogens present in both the tobacco and coal. We believe that further study is necessary to clarify and define the pathophysiological mechanisms where by shisha smoking may produce disease. We also believe that in the light of the evidence already available, public awareness of the potential effects of shisha smoking is required.

\section{References}

1 Maziak W. The waterpipe: an emerging global risk for cancer. Cancer Epidemiol 2013;37:1-4.

2 Kirby J. Health warning to shisha smokers. The Independent, 14 March 2012. Available online at www.independent.co.uk/life-style/ health-and-families/health-news/health-warning-to-shishasmokers-7565842.html [Accessed 27 February 2015].

3 Kadhum M, Jaffery A, Haq A, Bacon J, Madden B. Measuring the acute cardiovascular effects of shisha smoking: a cross-sectional study. JRSM Open 2014;5:2054270414531127.

4 Mughal F, Meki A, Kassamali RH. Shisha: is this addressed within smoking cessation in general practice? Br J Gen Pract 2014;64:173.

5 Al-Naggar RA, Saghir FSA. Water pipe (shisha) smoking and associated factors among Malaysian university students. Asian Pac J Cancer Prev 2011;12:3041-7.

6 Haroon M, Munir A, Mahmud W, Hyder O. Knowledge, attitude, and practice of water-pipe smoking among medical students in Rawalpindi, Pakistan. J Pak Med Assoc 2014;64:155-8. 
7 Grekin ER, Ayna D. Waterpipe smoking among college students in the United States: a review of the literature. J Am Coll Health 2012;60:244-9.

8 Amin TT, Amr MAM, Zaza BO, Kaliyadan F. Predictors of waterpipe smoking among secondary school adolescents in Al Hassa, Saudi Arabia. Int J Behav Med 2012;19:324-35.

9 Jawad M, Jawad S, Mehdi A, Sardar A, Jawad AM, Hamilton FL. A qualitative analysis among regular waterpipe tobacco smokers in London universities. Int J Tuberc Lung Dis 2013;17:1364-9.

10 Cobb CO, Sahmarani K, Eissenberg T, Shihadeh A. Acute toxicant exposure and cardiac autonomic dysfunction from smoking a single narghile waterpipe with tobacco and with a "healthy" tobacco-free alternative. Toxicol Lett 2012;215:70-5.

11 Sepetdjian E, Saliba N, Shihadeh A. Carcinogenic PAH in waterpipe charcoal products. Food Chem Toxicol 2010;48:3242-5

12 Hammal F, Chappell A, Wild TC et al. "Herbal” but potentially hazardous: an analysis of the constituents and smoke emissions of tobacco-free waterpipe products and the air quality in the cafes where they are served. Tob Control 2013;Oct 15:10.1136/tobaccocontrol-2013-051169, epub ahead of print.

13 La Fauci G, Weiser G, Steiner IP, Shavit I. Carbon monoxide poisoning in narghile (water pipe) tobacco smokers. CJEM 2012;14:57-9.

14 Eissenberg T, Shihadeh A. Waterpipe tobacco and cigarette smoking: direct comparison of toxicant exposure. Am J Prev Med 2009;37:518-23.

15 Al Numair K. Water-pipe (shisha) smoking influences total antioxidant capacity and oxidative stress of healthy Saudi males. Int J Food, Agric Environ 2007;5:17-22.

16 Shaikh RB, Vijayaraghavan N, Sulaiman AS, Kazi S, Shafi MSM. The acute effects of waterpipe smoking on the cardiovascular and respiratory systems. J Prev Med Hyg 2008;49:101-7.

17 Al-Safi SA, Ayoub NM, Albalas MA, Al-Doghim I, Aboul-Enein FH. Does shisha smoking affect blood pressure and heart rate? J Public Health (Bangkok) 2008;17:121-126.
18 Ghasemi A, Syedmoradi L, Momenan AA, Zahediasl S, Azizi F. The influence of cigarette and qalyan (hookah) smoking on serum nitric oxide metabolite concentration. Scand J Clin Lab Invest 2010;70:116-21.

19 Selim GM, Elia RZ, El Bohey AS, El Meniawy KA. Effect of shisha vs. cigarette smoking on endothelial function by brachial artery duplex ultrasonography: an observational study. Anadolu Kardiyol Derg 2013;13:759-65.

20 Wolfram RM, Chehne F, Oguogho A, Sinzinger H. Narghile (water pipe) smoking influences platelet function and (iso-)eicosanoids. Life Sci 2003;74:47-53.

21 Blachman-Braun R, Del Mazo-Rodríguez RL, López-Sámano G, Buendía-Roldán I. Hookah, is it really harmless? Respir Med 2014;108:661-7.

22 QuitShisha. The health effects of smoking shisha and hookah. Available online at http://www.quitshisha.com/ [Accessed 27 February 2015].

23 Akl EA, Gaddam S, Gunukula SK, Honeine R, Jaoude PA, Irani J. The effects of waterpipe tobacco smoking on health outcomes: a systematic review. Int J Epidemiol 2010;39:834-57.

24 Roohullah, Nusrat J, Hamdani SR, Burdy GM, Khurshid A. Cancer urinary bladder - 5 year experience at Cenar, Quetta. J Ayub Med Coll Abbottabad 13:14-6.

25 Hosseini M, SeyedAlinaghi S, Mahmoudi M, McFarland W. A case-control study of risk factors for prostate cancer in Iran. Acta Med Iran 48:61-6.

26 El-Hakim IE, Uthman MA. Squamous cell carcinoma and keratoacanthoma of the lower lip associated with "Goza" and "Shisha” smoking. Int J Dermatol 1999;38:108-10.

Address for correspondence: Prof B Madden, Cardiothoracic Unit, Ben Weir Ward, Atkinson Morely Wing, St George's Hospital, London SW17 0QT, UK.

Email: brendan.madden@stgeorges.nhs.uk

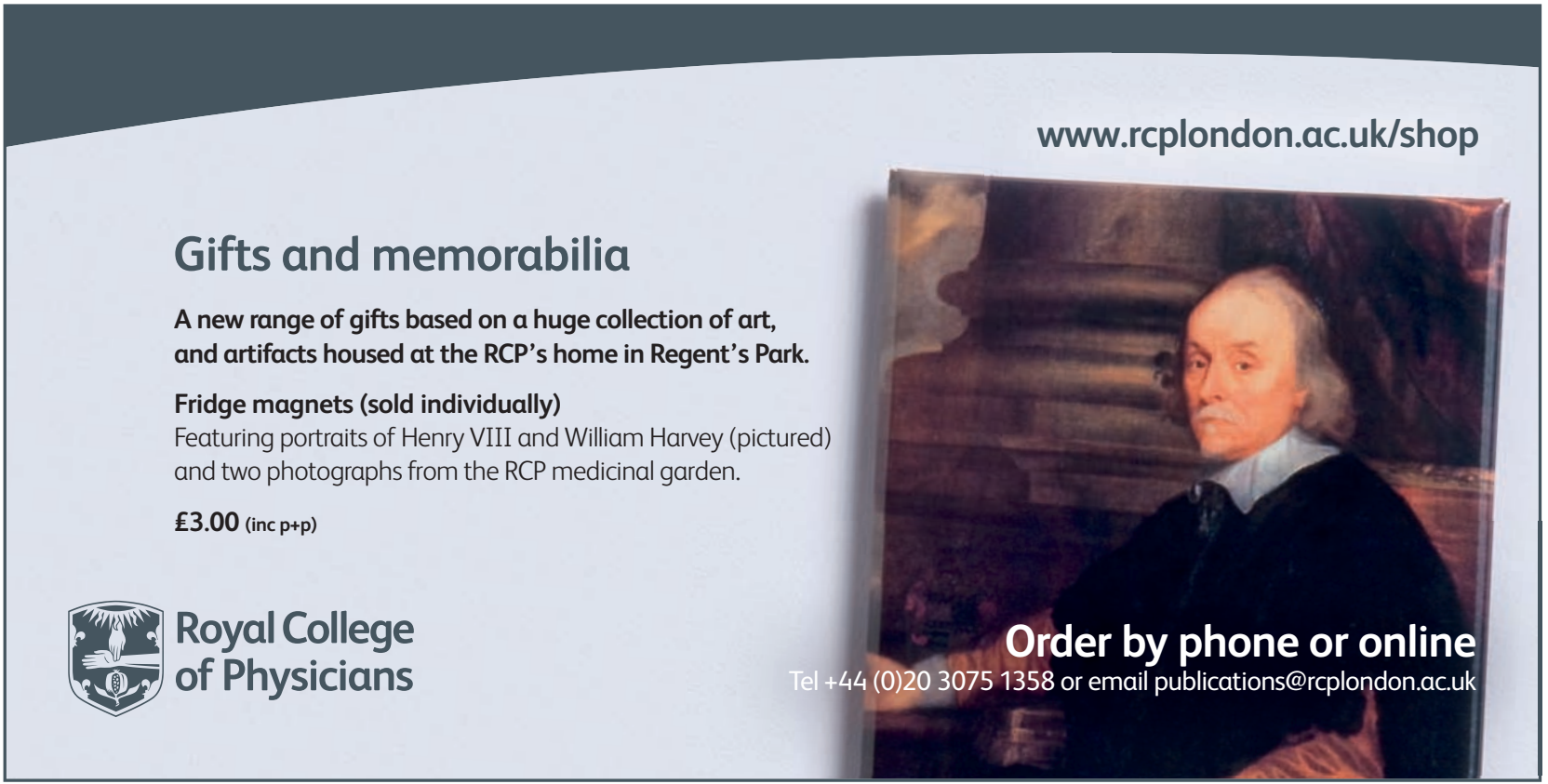

